\title{
Breeding custom-designed crops for improved drought adaptation
}

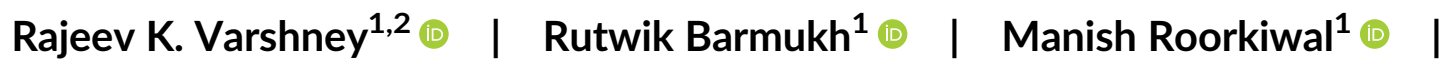 \\ Yiping Qi ${ }^{3,4}$ | Jana Kholova ${ }^{5}$ | Roberto Tuberosa ${ }^{6}$ | Matthew P. Reynolds ${ }^{7}$ | \\ Francois Tardieu $^{8}$ | Kadambot H. M. Siddique ${ }^{9}$ \\ ${ }^{1}$ Centre of Excellence in Genomics and Systems Biology, International Crops Research Institute for the Semi-Arid Tropics (ICRISAT), Hyderabad, India \\ ${ }^{2}$ State Agricultural Biotechnology Centre, Centre for Crop and Food Innovation, Murdoch University, Murdoch, Western Australia, Australia \\ ${ }^{3}$ Department of Plant Science and Landscape Architecture, University of Maryland, College Park, Maryland, USA \\ ${ }^{4}$ Institute for Bioscience and Biotechnology Research, University of Maryland, Rockville, Maryland, USA \\ ${ }^{5}$ Crop Physiology and Modelling, International Crops Research Institute for the Semi-Arid Tropics (ICRISAT), Hyderabad, India \\ ${ }^{6}$ Department of Agricultural and Food Sciences, University of Bologna, Bologna, Italy \\ ${ }^{7}$ International Maize and Wheat Improvement Center (CIMMYT), Texcoco, Mexico \\ ${ }^{8}$ Université de Montpellier, INRAE, Laboratoire d'Ecophysiologie des Plantes sous Stress, Environnementaux, Montpellier, France \\ ${ }^{9}$ The UWA Institute of Agriculture, The University of Western Australia, Perth, Western Australia, Australia
}

\section{Correspondence}

Rajeev K. Varshney, Centre of Excellence in Genomics and Systems Biology, International Crops Research Institute for the Semi-Arid Tropics (ICRISAT), Hyderabad 502324, India. Email: r.k.varshney@cgiar.org, rajeev.

varshney@murdoch.edu.au

\section{Funding information}

USDA-NIFA, Grant/Award Numbers: 2020-70029-33161, 2020-33522-32274, 2018-33522-28789; NSF, Grant/Award Numbers: IOS-2029889, IOS-1758745; Science \& Engineering Research Board (SERB) of Department of Science \& Technology (DST), Government of India; Ministry of Agriculture \& Farmers Welfare, Government of India; Department of Biotechnology, Ministry of Science \& Technology, Government of India; Bill \& Melinda Gates Foundation, USA

\begin{abstract}
The current pace of crop improvement is inadequate to feed the burgeoning human population by 2050 . Higher, more stable, and sustainable crop production is required against a backdrop of drought stress, which causes significant losses in crop yields. Tailoring crops for drought adaptation may hold the key to address these challenges and provide resilient production systems for future harvests. Understanding the genetic and molecular landscape of the functionality of alleles associated with adaptive traits will make designer crop breeding the prospective approach for crop improvement. Here, we highlight the potential of genomics technologies combined with crop physiology for high-throughput identification of the genetic architecture of key drought-adaptive traits and explore innovative genomic breeding strategies for designing future crops.
\end{abstract}

\section{KEYWORDS}

context-dependent optimization, drought physiology, genome editing, genomic breeding, root system architecture, speed breeding

\section{1 | INTRODUCTION}

Crop production must increase to meet the dietary needs of the global human population; however, this task is challenged by the fluctuating environmental conditions. The changing climate, referred to as "climate crisis," is heading us toward a warmer and drier Earth. ${ }^{1}$ In the last decade, global economic losses in agriculture stemming from drought totaled approximately US $\$ 29$ billion. $^{2}$ It is anticipated that water demand for agriculture could increase two fold by 2050 , with freshwater availability decreasing by up to $50 \%$ due to increasing

This is an open access article under the terms of the Creative Commons Attribution License, which permits use, distribution and reproduction in any medium, provided the original work is properly cited.

(c) 2021 The Authors. Advanced Genetics published by Wiley-VCH GmbH. 
climatic variations. Food security necessitates urgent investments in this domain, particularly for the development of high-yielding crops that are climate-resilient and more effective and/or efficient in using water than their prevailing counterparts. ${ }^{3}$

Conventional breeding programs have made impressive progress in the development of crop varieties adapted to drought conditions. ${ }^{4-6}$ However, this labor-intensive process often takes many years to advance from the preliminary stages of assessing phenotypes and genotypes to initial crosses into commercial varieties. Conventional breeding ignores the genetic variability of adaptive traits that underlie yield, at the risk of (indirectly) selecting only those alleles that are beneficial in all tested environments. ${ }^{7}$ The alleles thus selected are infrequent compared with those alleles whose effects are contextdependent. $^{8}$ By contrast, context-dependent optimization of traits has the potential to maximize positive effects on yield under specific environmental conditions. Therefore, to improve the production of adapted varieties, future breeding programs must combine desirable plant traits that complement climate, soil, and management practices (eg, sowing dates, fertilization, plant density, etc.) in target production systems.

Plant genomics plays a key role in improving crops, advancing environmental resilience and productivity. ${ }^{9}$ Technical innovations in applied genomics coupled with the availability of large-scale sequencing data provide us with the capabilities for identifying genetic variation that underlies increasing crop performance and improving the efficiency of breeding. ${ }^{10-12}$ Furthermore, biotechnological approaches, including targeted genome editing using CRISPR-Cas technologies, have expedited advances in the temporal and spatial regulation of genes and major pathways for drought adaptation. ${ }^{13,14}$ A comprehensive understanding of the adaptive mechanisms under distinct drought scenarios is crucial for securing future harvests and fuelling the necessary genetic gain in crop improvement. Such gains can be driven by genetic variability and deployed by genomic breeding, more precise genetic modifications, and tailored management practices.

In this review, we start by discussing the major advances in crop leaf and root research associated with drought adaptation, and then describe how the context-dependent optimization of above- and below-ground traits offers opportunities to improve future crops. We discuss recent innovations in genomic breeding approaches that empower design-based crop improvement, including haplotype-based breeding, genome editing, systems biology, and genomic selection. Finally, we explore how speed breeding could interact with new-age genomic breeding technologies to speed-up crop development. Our goal is to provide a comprehensive overview of the processes related to drought and highlight possible ways to develop future crops in the face of increasing climatic fluctuations.

\section{2 | PHYSIOLOGICAL ADAPTATIONS TO DROUGHT}

In times of drought, crops dynamically manage their water balance by: (a) limiting water loss by reducing leaf area and stomatal conductance ${ }^{15,16}$; (b) enhancing soil water uptake by altering root growth and architecture ${ }^{17,18}$; and (c) osmotic adjustment (OA), via accumulation of solutes in the cells. ${ }^{19}$ Here, we discuss some of the key adaptive traits in further detail.

\section{1 | Limiting water loss}

Crops exposed to soil water deficit need to preserve available water by limiting transpiration while, in parallel, fixing adequate carbon to meet energy demands. Reduction in leaf area and stomatal conductance display a rapid response against dehydration by limiting the transpiration rate, thus budgeting soil moisture and maintaining increased leaf water potential levels. For instance, drought adaptation of stay-green (Stg) sorghum is linked to reduced green leaf area at anthesis, lower tillering, and smaller upper leaves. ${ }^{15}$ These mechanisms facilitate remarkable plasticity to the crop for modulating canopy development in response to the intensity of drought stress. Furthermore, reduced stomatal conductance and transpiration rate, leading to better water-use efficiency, enable increased drought adaptation in wheat. ${ }^{20}$ Low stomatal density also improves drought tolerance and water conservation properties in rice ${ }^{16}$ and barley. ${ }^{21}$ Leaf growth is mainly determined by vapor pressure deficit and available soil moisture, with a large genetic variability in the sensitivity to both conditions. As a result, leaf area evaluated at any particular time point is a consequence of the prevailing environmental conditions and genotype-dependent sensitivity. Canopy development traits are mainly driven by leaf area, ${ }^{15}$ which is affected by other factors such as tillering or phyllochron, all of which depend on drought severity with genotype-dependent sensitivities. Therefore, if the phenotypes associated with leaf area are to be included in broader research and breeding programs, precise and dynamic measurement of leaf area becomes essential. Phenotyping systems are being developed that strategically target leaf traits which are crucial and relatively easy to measure at the single-leaf or whole-canopy levels, and in some cases by remote sensing with drones. ${ }^{22,23}$

\subsection{Enhancing water uptake}

The root system is the interface for soil water and nutrient acquisition, and physically anchors the plant to the soil substrate. In a plant root system, the coarse (or tap) roots play a role in plant anchorage and usually establish root system architecture, regulate rooting depth, and the capability of the plant to grow in dense soil layers. In contrast, fine (or lateral) roots are actively involved in water uptake, and mostly comprise of the length and surface area of the root system. ${ }^{24}$ Root architecture and its capability to acclimate in response to environmental fluctuations are key factors determining overall plant robustness. ${ }^{18,25,26}$ During soil water deficit, root systems change structurally to improve water and nutrient uptake from the soil profile. For instance, in soil environments with heterogeneous moisture distribution, roots can demonstrate hydro-patterning, with a preference for lateral root emergence toward soil zones with higher water content, a 
process facilitated by auxin signaling. ${ }^{27}$ Using maize roots, it is experimentally demonstrated that growth is essential for perception of water availability to pattern lateral roots in plants. ${ }^{17}$ Hydrotropism represents another adaptive root response, where root tips propagate toward soil patches containing higher moisture content to optimize water procurement. ${ }^{28}$ Furthermore, root respiration provides the energy for root growth and maintenance, absorption of water molecules and ions followed by their transport into the xylem, highlighting the root physiological metabolic capability. A decline in root respiration and root biomass under severe water deficit is associated with improved grain yields and high drought adaptation in wheat cultivars. ${ }^{29}$ Root system architecture is becoming a key target for crop improvement; however, progress in this domain has been fairly slow, partly owing to challenges with efficient phenotyping of roots. ${ }^{30,31}$ From a breeding viewpoint, more effective phenotyping approaches, which can evaluate large mapping populations or germplasm lines for proxies in the field and genetic variability of root characteristics on phenotyping platforms, are required to incorporate root traits in crop improvement programs.

\subsection{Osmotic adjustment}

$\mathrm{OA}$ is a metabolic process that plays a key role in drought adaptation through turgor maintenance and the protection of defined cellular functions by intercellular solutes. ${ }^{19}$ OA has been implicated in supporting crop yield under drought conditions. For instance, high OA wheat cultivars maintained better growth and yield, both of which were linked to enhanced leaf water potential relative to low OA cultivars. ${ }^{32}$ Mahmood et al. ${ }^{33}$ measured OA in 30 wheat genotypes subjected to well-watered and drought stress conditions in the field. Here, OA was positively associated with kernel weight that directly contributed to yield, suggesting that wheat achieves OA to uptake more soil water during low water potential. A significant and positive correlation was observed between yield and OA capacity under terminal drought stress conditions in barley. ${ }^{34}$ Further, Moinuddin and Imas $^{35}$ evaluated eight chickpea varieties for $\mathrm{OA}$ and specific osmolytes such as sugars, proline, nitrogen, and potassium. The contribution of the osmolytes to OA became more crucial with an increase in water deficit toward the reproductive stage. Here, grain yield showed a linear and positive correlation with high OA and relative water content under water deficit. The importance of OA as a preferable selection target from a breeding viewpoint has been a continuing trickle of skepticism. This is mainly due to the belief that drought-adaptive genotypes with a better ability to adjust osmotically are typically characterized by slow growth and limited biomass production, because of metabolic needs for osmolyte biosynthesis. Under severe drought stress, increased accumulation of osmolytes may help crops withstand a prolonged drought episode and go through a more prompt and complete recovery after rehydration. ${ }^{32}$ OA by maintaining turgor in wheat exposed to slow drying soil, helps to partially sustain stomatal conductance, photosynthesis, and dry biomass accumulation at low levels of leaf water potentials. ${ }^{36}$ Importantly, the trade-off between metabolic costs associated with OA and the potential advantages to the crop differs on a case-to-case basis as a function of the genotype, and the dynamics and intensity of drought scenarios.

\section{3 | TRAIT-BASED BREEDING FOR DROUGHT ADAPTATION}

Seed yield is usually the selection criterion when breeding crops for drought adaptation. However, yield is a complex and final-stage trait, which is influenced by the environmental interaction with growth and development processes that occur throughout the crop cycle. A conventional breeding strategy aimed at improving performance under drought by selecting genotypes merely based on higher absolute yields is predicted to fall short of meeting future crop production demands. ${ }^{37}$ Limited genetic variation in yield among improved cultivars, high genotype $\times$ environment $\times$ management $(G \times E \times M)$ interactions, and low heritability are some critical factors that could restrict future crop improvement efforts through direct selection for yield. ${ }^{38}$ By contrast, the genetic improvement of adaptive traits (such as biomass, harvest index, canopy temperature, etc.) through changes in leaf and/or root ideotypes hold enormous potential to increase productivity and genetic gain under drought conditions, as demonstrated in wheat. ${ }^{39}$ This is because such traits are genetically more variable among present-day cultivars and have not been the target of conventional breeding efforts. ${ }^{40}$ Designing a crop with better adaptation to drought conditions demands a major effort in improving such adaptive traits. Therefore, a trait-based strategy that evaluates genotypes on the basis of physiological responses to water deficit at the initial stages of plant growth could be more targeted to drought and time efficient.

\section{4 | CONTEXT-DEPENDENT OPTIMIZATION PROBLEM}

Many drought-adaptive traits often possess a twofold effect: positive in severe terminal stress conditions and negative in favorable (or milder drought stress) conditions, or vice versa. ${ }^{7}$ Remarkable results obtained in one drought scenario might confer only limited productivity gains in other geographical areas experiencing water deficit. Moreover, genetic trade-off among adaptive traits may also occur. For example, in wheat sister lines, investment in deeper root systems tended to be offset by reduced storage of water soluble carbohydrates in stems, the latter being important if sub-soil water is unavailable. ${ }^{41}$ We highlight the context-dependent effects of major drought-adaptive traits on yield under water deficit.

\section{$4.1 \quad$ Leaf area}

For environments that experience long and severe drought episodes, genotypes possessing a small leaf area or reduced transpiration have an advantage, as they retain soil water for later phases of the crop 
cycle for grain filling (Figure 1). ${ }^{42,43}$ For example, a reduced transpirational leaf area in sorghum Stg near-isogenic lines relative to their recurrent parent under severe water deficit enabled increased water extraction during grain filling, leading to better biomass production, grain number, and grain yield. ${ }^{44}$ Simulation modeling across a range of climatic scenarios and management practices suggests that reduced leaf area confers a yield reward under severe drought stress but negatively impacts crop yield and biomass accumulation under less severe circumstances in crops such as maize ${ }^{45}$ and sorghum. ${ }^{46}$ By contrast, under rainfed field conditions that usually experience sporadic drought patterns, the ability to maintain leaf area during soil water deficit is mainly responsible for determining crop yields (Figure 1). For instance, simulation modeling revealed that early vigor traits in wheat resulted in up to $16 \%$ yield advantage via genotypes possessing doubled early leaf size, at wetter sites or years. ${ }^{47}$ Importantly, the maintenance of leaf growth characteristics could confer four major benefits to the crop: (a) a higher photosynthesis at canopy scale, in particular during the pre-flowering stage that affects grain number ${ }^{48}$; (b) a reduction in soil water evaporation, while facilitating efficient use of water via transpiration ${ }^{47}$; (c) a drop in leaf temperature due to higher transpiration rate ${ }^{49}$; and (d) a decrease in seed abortion rate caused by source-sink relationships. ${ }^{50}$

\section{2 $\quad$ Root architecture}

A deep, wide-spreading, and branched root system is beneficial for most crops grown in deep soils under moisture deficit conditions. ${ }^{18,51}$
This notwithstanding, breeding programs focused on improving grain yield under drought have often resulted in the development of crop varieties with reduced root biomass. ${ }^{52,53}$ This is mainly because, the spatial distribution of roots in the deep soil profile, but not root biomass or root length, governs the capability of root systems to efficiently uptake soil water. For instance, increased root distribution in deep soil layers ( $>30 \mathrm{~cm}$ soil depth) facilitated better water uptake and adaptation in drought tolerant chickpea genotypes. ${ }^{54}$ Therefore, longer and deeper roots with compact branching angles could be accompanied by high root length density in the deep soil profile to precisely capture water from the soil, which is dry at the surface but holds moisture in deeper layers (Figure 1). Soil nutrients such as phosphorous, potassium, iron, and manganese, are immobile and usually present in the upper soil layers. Hence, it should be considered that a substantial increase in root length density in the deep soil layers at the expense of upper layers would limit nutrient acquisition from the top soil and may be associated with crop yield penalties. ${ }^{55}$ By contrast, in shallow soils that receive intermittent rainfall during the crop growing season or under optimal soil moisture conditions, an extensive, broad and shallow root system is preferable for enhancing crop productivity (Figure 1).

\section{3 $\quad$ Crop cycle duration}

Drought escape is an adaptive mechanism that involves the rapid development of a plant to complete its entire life cycle prior to the onset of drought stress. Following the concept of drought escape, the duration

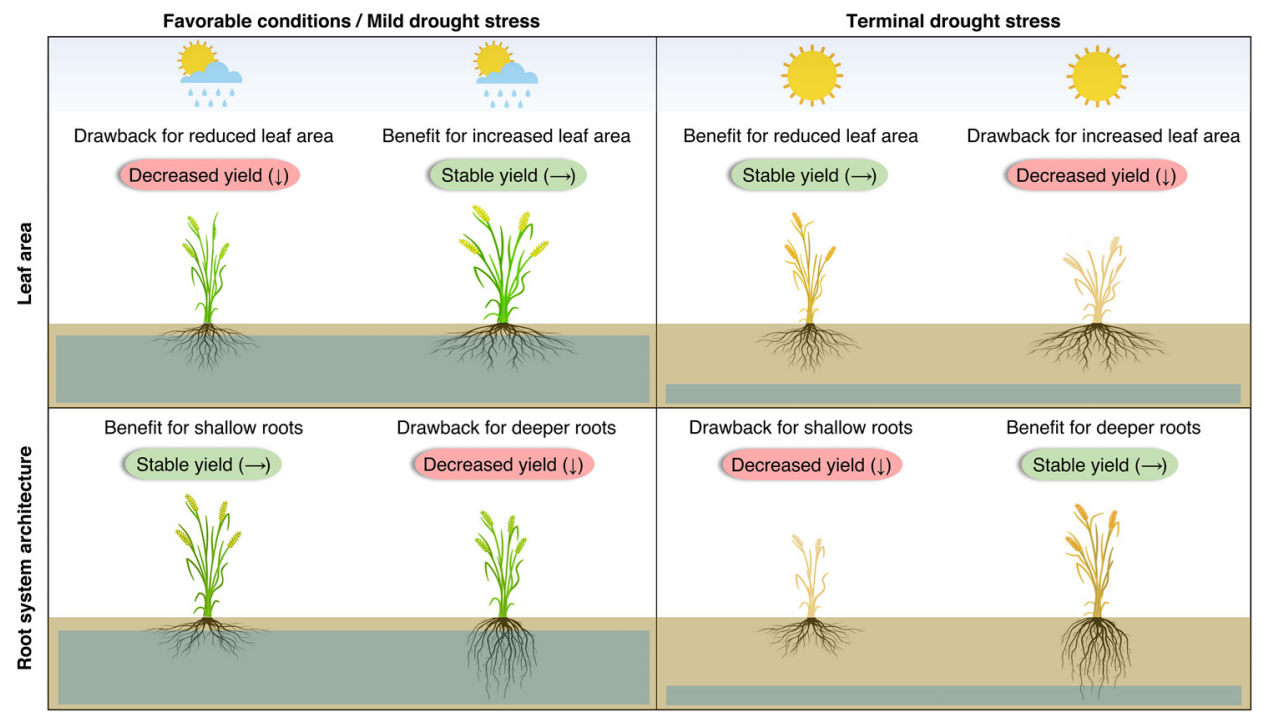

FIGURE 1 Yield benefits and drawbacks linked to leaf area and root system architecture under different drought scenarios. The most advantageous leaf and root phenotype is highly context-dependent and impacted by several components, including climate, soil, or management. Reduced leaf area retains soil moisture and decreases hydraulic gradients, and is associated with yield reward under terminal severe stress; whereas, it lowers cumulative photosynthesis during the crop cycle and displays a yield penalty under favorable conditions/mild drought stress. Deeper roots increase water uptake from very deep soil layers and possess yield reward under terminal severe drought stress conditions where deep water is available; whereas, it leads to a lower nutrient uptake and is suboptimal under favorable conditions for nutrient foraging in upper soil layers 
of the crop cycle, which is mostly determined by genes affecting flowering time, also plays a critical role in enhancing productivity under water deficit. A long crop cycle is advantageous under favorable conditions, since it increases the interception of incident solar radiation, but is associated with a yield penalty under severe terminal drought, because it depletes soil water reserves before the end of the crop cycle. ${ }^{7}$ This was found to be true for wheat genotypes selected in Mediterraneantype climates with frequent occurrences of terminal drought stress, where modern varieties with a drought escape strategy showed substantially higher production due to reduced risk of water stress during reproductive or grain filling stages. ${ }^{56,57}$ The concurrent confounding effects of phenology-related components, such as the duration of vegetative period, flowering time, and crop cycle as the major factors affecting water uptake, suggest that interactions of these traits with specific leaf or root ideotypes can be explored through a combination of experiments and modeling (Boxes 1 and 2).

Taken together, the substantial context-dependency accompanied with above- and below-ground plant traits, highlights the need for more targeted studies considering $G \times E \times M$ interactions in crops to stabilize yields in fluctuating environments. ${ }^{58}$

\section{5 | HARNESSING GERMPLASM DIVERSITY}

A major constraint for tailoring crop varieties is the limited genetic diversity for key traits available in modern crop gene pools, mainly due to domestication and breeding bottlenecks. ${ }^{59}$ National and international gene banks contain a great source of diverse alleles and may hold the key to addressing this limitation. Three major categories of genetic resources can be explored, namely crop wild relatives, secluded gene pools (eg, landraces), and modern breeding lines.

Evaluating large germplasm collections for identifying variation in drought-adaptive traits may not always be feasible. In such cases, selecting an economically feasible set of accessions with a higher probability of capturing beneficial allelic variation is much more preferable. ${ }^{60}$ The Focused Identification of Germplasm Strategy (FIGS) was used to enhance the efficiency of detecting specific drought-adaptive traits from faba bean germplasm collections. ${ }^{61}$ FIGS utilizes agro-ecological data to generate a priori information, which is then used to identify a group of accessions possessing the desired adaptive traits. An impressive illustration of this strategy came from a recent field evaluation of FIGS wheat panels prioritized based on tolerance to drought stress, which revealed over $45 \%$ of lines having greater plant biomass under drought than the adapted check varieties. ${ }^{62}$ With better access to the genetic variability found in natural populations of wild relatives and landraces, the door is open for retrieving drought-adaptive traits; several of which are encoded by alleles that disappeared in domesticated crops, or which evolved individually in diverse crop lineages. ${ }^{60}$

Next-generation sequencing and high-throughput genotyping platforms can be used to characterize allelic diversity in genetic resources, ${ }^{63}$ and suitable lines carrying desired combinations of alleles can be used to develop specific leaf and/or root ideotypes for target environments. ${ }^{64}$ Recent sequencing efforts, including The 3000 Rice

\section{BOX 1 A probabilistic approach for drought adaptation}

A deeper understanding of the dual effects of most drought-adaptive traits is crucial for tailoring future crops with a phenotype matching the target climatic scenarios. In theory, custom-designed crops should carry a genetic predisposition for a particular leaf or root architecture together with mechanisms allowing growth plasticity in response to water deficit, as observed in wheat. ${ }^{26}$ This could significantly increase a crop's ability to maximize resource capture from the surrounding environment while reducing the impact associated with climatic fluctuations. The contextdependency of nearly every trait on yield needs a two-step approach: (a) identify the combination of alleles that influence the response of studied traits to environmental conditions, and (b) detect the response of yield to traits or allelic combinations in most frequent scenarios sensed by plants in a given region. ${ }^{7}$ To this end, Millet et al. ${ }^{48}$ suggested a simplified approach using a regressive model of responses to environmental conditions in maize, with genotypedependent sensitivities that were modeled by genomic prediction. This consisted of three major phases: (a) to establish response curves of yield components to soil water deficit, evaporative demand, and light in a multi-site field experiment; (b) to simulate the sensitivity of each genotype based on genomic prediction; and (c) to predict yield of hundreds of genotypes in hundreds of fields in which drought stress differed between years. Because farmers do not know at the time of sowing the actual environmental scenario that will be sensed by plants, the choice of genotype will ultimately depend on the probability of environmental scenarios in each farmers' field, ${ }^{45}$ and the farmers' own choice between maximum gain versus risk avoidance. Such a probabilistic approach, which is based largely on the genetic variability of adaptive traits and on their context-dependent effects, may eventually assist breeders to improve drought adaptation of major field-grown crops.

Genome $^{65}$ and The 3000 Chickpea Genome ${ }^{66}$ hold promise to provide novel insights into intra-species genetic variation and evolutionary crop history. The integration of gene bank passport data and weather data from the target population of environments (TPE) can be utilized to identify superior haplotypes for specific adaptive traits, which could be used in haplotype-based breeding (discussed below). ${ }^{11}$ Additionally, deleterious alleles (genetic load) associated with the trait(s) of interest could be identified by utilizing genomic evolution parameters and amino acid conservation modeling, as demonstrated in cassava ${ }^{67}$ and chickpea, ${ }^{66}$ and eliminated using molecular breeding or genome editing strategies. ${ }^{68}$ As a result, superior parental lines 


\section{BOX 2 Glossary}

\section{ADAPTIVE TRAIT}

A phenotypic trait that differs with existing environmental scenarios for a particular genotype, and which can maximize fitness or production in specific environmental conditions.

\section{ANTHESIS}

The period during which a flower is completely open and functional.

\section{DROUGHT ADAPTATION}

The ability to sustain biomass production or crop yield, despite the occurrence of drought episodes during the crop cycle.

\section{ENVIRONMENTAL SCENARIO}

A clustered pattern of time courses for soil moisture status, evaporative demand, light, and temperature in diverse fields (a particular field can experience different scenarios in different years).

\section{EXPRESS EDIT}

A system that incorporates gene editing directly in the speed breeding system, and has the potential to bypass the bottlenecks of in vitro manipulation of plant materials.

\section{GENE REGULATORY NETWORK (GRN)}

A group of molecular factors (genes, RNA, and proteins) that interact directly or indirectly with each other and together influence a biological process of interest.

\section{GENETIC GAIN}

Improvement in the average genetic value in a population or in the average phenotypic value due to selection within a population over multiple cycles of breeding.

\section{GENOMIC BREEDING}

A breeding approach that uses "-omics" data, knowledge resources, genes, and technologies, developed from genomics and genome editing research for crop improvement.

\section{HAPLOTYPES}

A group of alleles within an organism that are inherited together from a single parent.

\section{HAPLOTYPE-BASED BREEDING}

A promising breeding approach for developing custom-made crop varieties by introgressing superior haplotypes in elite breeding lines.

\section{HARVEST INDEX}

Harvest index is defined as the ratio of harvested grain to total shoot dry matter, and it can be used as a measure of reproductive efficiency.

\section{HYDRO-PATTERNING}

A root developmental response where lateral roots preferentially initiate to the side in contact with water.

\section{HYDROTROPISM}

The directed growth of roots toward water or moisture gradients.

\section{HYPERSPECTRAL IMAGES}

Refers to the images in which one continuous spectrum is measured for each pixel.

\section{IDEOTYPE}

A biological model that is anticipated to perform in a predictable manner within a specific Environment.

\section{LEAF WATER POTENTIAL}

Indicates the whole plant water status and contributes to plant-level physiological drought adaptation.

\section{LINKAGE DRAG}

The undesirable effects of deleterious alleles genetically associated with the desired trait.

\section{OSMOTIC ADJUSTMENT}

A reduction in osmotic potential attained by the accumulation of solutes in response to osmotic stress.

\section{OSMOLYTE BIOSYNTHESIS}

The synthesis and accumulation of diverse osmolytes in plants for combatting osmotic and oxidative stress. 


\section{PHYLLOCHRON}

The time interval between the appearances of successive leaves on the main stem of the plant.

\section{PROTOSPACER ADJACENT MOTIF (PAM)}

The DNA motif flanking the target sequence that is indispensable for target recognition and cleavage by CRISPR-Cas systems.

\section{SPEED BREEDING}

A breeding strategy that greatly shortens generation time in plants, by using supplemental lighting under glasshouse conditions and by extending the photoperiod to a day-length of 22 hours.

\section{STOMATAL CONDUCTANCE}

A measure of the rate of carbon dioxide uptake and water loss (viz. transpiration) through the stomata of a leaf, as evaluated by the degree of stomatal aperture.

\section{SYSTEMS BIOLOGY}

A holistic approach for deciphering the complexity of biological systems that starts from the understanding that networks that form the whole of living organisms are more than the sum of their parts.

\section{TARGET POPULATION OF ENVIRONMENTS (TPE)}

The set of fields and future climate scenarios in which the crop varieties produced by a breeding program will be grown.

\section{TILLERING}

The production of lateral shoots by a plant, mostly a grass or cereal, from the base of the stem.

containing preferred alleles at each locus and with minimum undesirable genetic load could be identified and integrated into breeding programs to tailor crops with desired allelic combinations.

\section{6 | INNOVATIVE GENOMIC BREEDING STRATEGIES}

Given the enormous genetic diversity available in germplasm repositories, extracting meaningful information from these resources require new-age breeding strategies. Genomic breeding plays a significant role in crop improvement, ${ }^{69}$ as highlighted by the development of a large number of improved field-grown crops with better adaptation to drought conditions (Table 1). Some genomic breeding approaches are being successfully used in major crops such as rice, wheat, maize, etc. in the highly industrialized world. However, crops grown in marginal environments such as pearl millet, sorghum, chickpea, pigeonpea, and cassava remain largely eluded from this success. Drought and desertification in the dryland regions result in an estimated loss of 12 million hectares of land every year, which accounts further in a loss of 20 million tons of food grain production. ${ }^{84}$ This demands an urgent investment in improving the drought adaptation of dryland crops using modern technologies, for ensuring future food security. Here, we describe how genomic innovations coupled with modern breeding efforts offer opportunities for designing drought-adaptive crops across the world, particularly in South Asia and Sub-Saharan Africa.

\section{1 | Haplotype-based breeding}

Plant breeding depends on recombination to combine preferred combinations of traits for developing improved crop varieties. Traditional breeding uses the heritability of phenotypes as a key criterion to evaluate genetic combinations. The genomic regions defined by quantitative trait loci (QTLs) typically contain multiple candidate genes and genetic variations, which either do not confer desired traits or possess harmful effects. Combinations of genomic loci that contribute to the preferred phenotype can be considered as groups of haplotypes that are determined by underlying genetic variation. Use of such genomic information enables the breeder to select superior haplotypes for designing ideal crop varieties in silico and deploy them in breeding programs. We refer to this concept as haplotype-based breeding, representing the evolution and a much more accurate version of "breeding by design". 85

The retrospective and prospective approaches suggested by Bevan et al. ${ }^{11}$ hold great potential for deploying a haplotype-based breeding strategy to develop drought-adaptive crops. In the retrospective approach, the genomic regions and the underlying haplotypes preferred by breeders over time can be identified by sequencing the genomes of important breeding lines, which have been widely evaluated across multiple environments and years in past decades. This will provide an overview of the breeders' selection decisions over time and help determine superior haplotypes related to previous breeding success. This approach was demonstrated recently by identification of candidate genes and signatures of artificial selection associated with seed size and weight using sequencing data for 200 accessions of cultivated flax (Linum usitatissimum L.). ${ }^{86}$ Furthermore, the information acquired by employing a retrospective approach can be used to identify the function of genomic regions containing the haplotypes, referred to as haplotigs, ${ }^{87}$ and determine the underlying desired and deleterious alleles associated with adaptive traits. By contrast, a prospective approach can be utilized by sequencing large ancestral populations and undomesticated crop varieties, to determine conserved inherited haplotigs with huge genetic variation and to identify 
TAB LE 1 Key success stories of genomic breeding strategies to improve drought adaptation and grain yield in field-grown crops

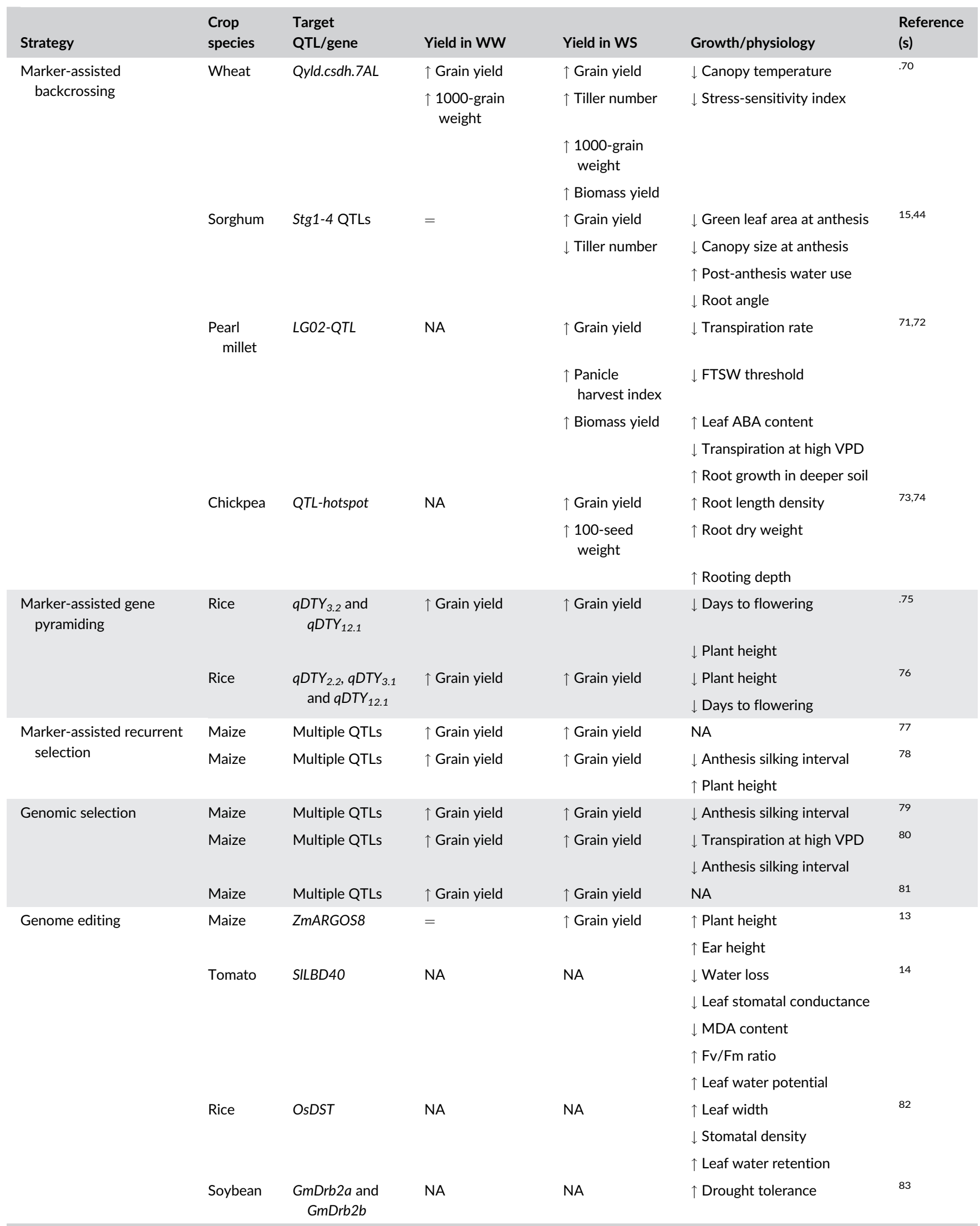

Abbreviations: ABA, abscisic acid; FTSW, fraction of transpirable soil water; MDA, malondialdehyde; NA, not available; QTL, quantitative trait locus; VPD, vapor pressure deficit; WS, water-stress conditions; WW, well-watered conditions. $\uparrow$, increased; =, maintained; $\downarrow$, decreased. 
combinations of superior haplotypes. This approach was used in a recent study to detect superior haplotypes for key genes related to drought tolerance component traits, which can be deployed in haplotype-based breeding of pigeonpea. ${ }^{88}$

Haplotype-based breeding represents a promising strategy for crops in which large germplasm collections are characterized both at the sequencing and phenotyping level. Assembling desired haplotype combinations in elite crop varieties will enable informed decisionmaking in breeding programs. ${ }^{69}$ For instance, a combination of superior haplotypes of previously validated genes that confer small leaf area, deeper root system, early flowering, and higher yield can be used to design crop ideotypes for improved adaptation to terminal drought stress (Figure 2). Taken together, haplotype-based breeding is expected to design future crops with desired adaptive traits, while demanding less monetary investment and in the absence of challenging public acceptance.

\section{2 | Genome editing}

Introgression of desired traits into an elite variety is often impaired by the random nature of recombination and linkage drag, making conventional breeding a time-consuming and laborious process. Heavy dependence on natural or random genetic diversity is a major constraint delaying the breeding process and leading to an unpredictable outcome. $^{89}$ In contrast, genome editing holds enormous potential to generate precise, efficient, and targeted alterations in crop plants. It can be performed with any crop, including those that possess complex genome architecture and are not readily bred using conventional approaches. ${ }^{90}$ The recent development of clustered regularly interspaced short palindromic repeats (CRISPR)-CRISPR-associated nuclease protein (Cas) systems have brought genome editing into the limelight. $^{13,91}$ Several gene knockout, insertion or replacement mutants are developed by CRISPR-Cas9-mediated editing in fieldgrown crops to improve their drought adaptation characteristics (Table 1).

Technical breakthroughs in the genome editing toolkit provide opportunities to exploit mutations giving rise to optimal shoot and/or root architecture for designing crops for the future. CRISPRCas9-mediated base editing is one such example, which can precisely change one DNA base into another in the absence of a DNA repair template. ${ }^{92,93}$ Recent development of a PAM-less CRISPR-SpRY toolbox, which disrupts a PAM restriction barrier of targeting only GC-rich DNA regions, has greatly expanded base editing scope in crops. ${ }^{94}$ Traditional transgene-mediated CRISPR-Cas delivery techniques (Figure 3) may be linked with undesirable genetic changes, ${ }^{95}$ with extended breeding cycles and regulatory constraints. Therefore, ribonucleoprotein (RNP)-based DNA-free genome editing ${ }^{96}$ is considered a major leap toward developing genome-edited crops with a lower risk of undesired off-target modifications, and satisfying present and future agricultural needs from a regulatory perspective. This technology has been accomplished in grapevine and apple through protoplast transformation, $^{97}$ in bread wheat via in planta particle
(A)

Gene

\begin{tabular}{|c|c|c|c|c|c|c|c|c|c|c|c|}
\hline \multirow{4}{*}{ Haplotypes } & $\mathrm{H} 1$ & $T$ & C & $G$ & $T$ & A & G & $T$ & G & A & G \\
\hline & $\mathrm{H} 2$ & $\mathrm{~T}$ & C & A & C & A & $\mathrm{T}$ & $\mathrm{T}$ & G & A & C \\
\hline & $\mathrm{H} 3$ & A & C & $\mathrm{G}$ & C & $A$ & G & $T$ & G & $T$ & C \\
\hline & $\mathrm{H} 4$ & $A$ & C & A & C & C & $G$ & A & $G$ & $T$ & $G$ \\
\hline
\end{tabular}

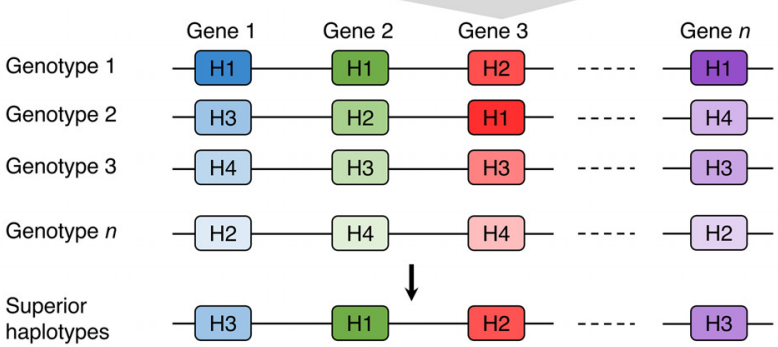

(B)

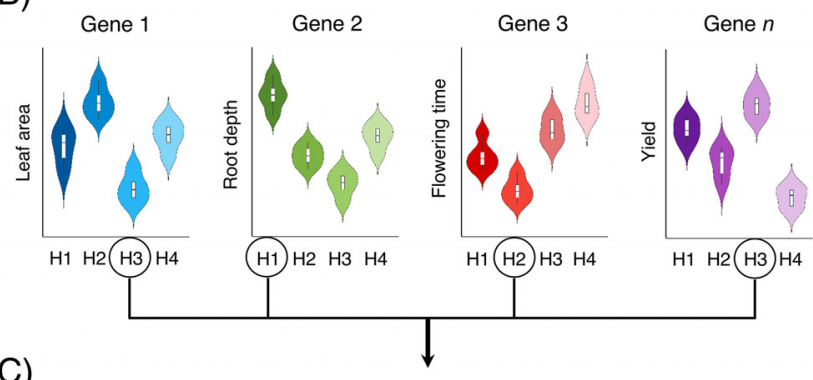

(C)
Inferior haplotypes

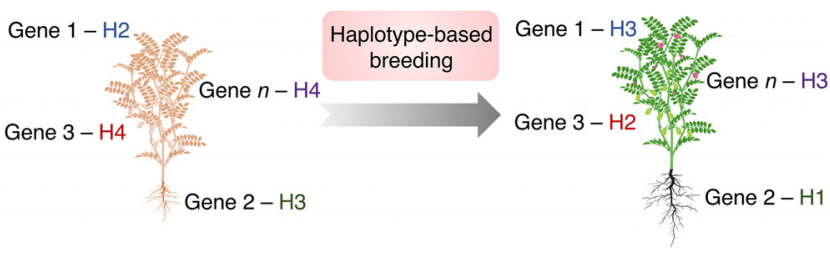

Elite variety

(drought susceptible)
Introgression line (drought-adaptive)
FIGURE 2 Haplotype-based breeding scheme for designing drought-adaptive crops. (A) An example of haplotypic variation (H1-H4) underlying a particular gene (gene 3 ) on a chromosome. A combination of various haplotypes for different genes (gene 1, gene 2 , gene 3 , gene $n$...) has been shown in multiple genotypes (genotype 1 , genotype 2 , genotype 3 , and genotype $n$ ). Superior haplotypes are selected for various genes based on the preferred combinations of phenotypes, expressed by the respective haplotype. (B) Difference in the performance of four traits associated with drought adaptation that are influenced by genetic variation in gene 1 (leaf area), gene 2 (root depth), gene 3 (time to flower) and gene $n$ (yield), is illustrated using violin plots. Analysis of variance results indicate that $\mathrm{H} 3$ is the superior haplotype for gene $1, \mathrm{H} 1$ for gene $2, \mathrm{H} 2$ for gene 3 , and $\mathrm{H} 3$ for gene $n$. (C) Introgression of superior haplotypes for multiple adaptive traits in an elite variety using haplotype-based breeding approach will enable development of an introgression line possessing improved drought adaptation

bombardment, ${ }^{98}$ and in tobacco by virus infection ${ }^{99}$ (Figure 3). The newly emerged CRISPR-Cas12a ${ }^{100}$ (formerly Cpf1) and Cas12b ${ }^{101}$ (formerly C2c1) systems have several key advantages over Cas9, such as preferring T-rich PAMs (enabling alternative targeting sites to 


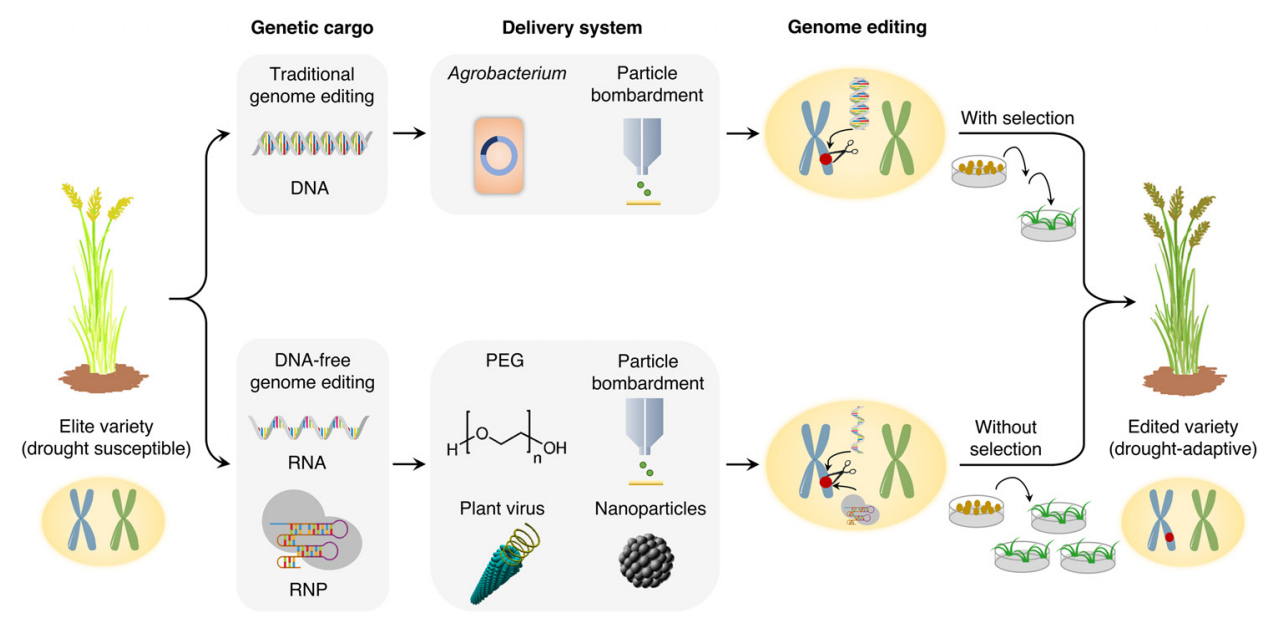

FIGURE 3 Strategies for delivery of CRISPR-Cas systems to plants. Traditional delivery systems for genome editing include CRISPR-Cas DNA together with selection pressure. Genetic segregation via selfing and crossing results in the development of transgene-free plants. Transient delivery methods for DNA-free genome editing involves the use of CRISPR-Cas reagents, such as RNA and ribonucleoproteins (RNPs). CRISPRCas reagents degrade after transient expression, and the edited plants can be regenerated without applying any selection pressure. DNA, deoxyribonucleic acid; mRNA, messenger RNA; RNP, ribonucleoprotein; PEG, polyethylene glycol

Cas9), and generating staggered ends of DNA double stranded breaks as opposed to blunt ends created by Cas9. Hence, the application of CRISPR-Cas12a and Cas12b could provide attractive alternatives to CRISPR-Cas9 systems in designing crop ideotypes for specific drought environments.

Drought adaptation processes in crops are often regulated by complex genetic mechanisms with the combined expression of numerous genes. Based on Golden Gate and Gateway assemblies, multiplex CRISPR-Cas expression systems have been developed for different applications in plants. ${ }^{102}$ For example, multiplex CRISPR-Cas systems have been used for generating quantitative trait variation in tomato by editing cis-regulatory elements in the promoter ${ }^{103}$ and for de novo crop domestication by simultaneous editing of multiple trait genes in wild tomato. ${ }^{104}$ Furthermore, a fusion of diverse effector domains to catalytically inactivated Cas (dCas) proteins has repurposed CRISPR systems for transcriptional regulation and epigenome editing in plants. ${ }^{105}$ Such innovative genome editing strategies could be harnessed to tailor shoot and root architectural traits in customdesigned crops. Moreover, the integration of speed breeding (see later) with genome editing technology, referred to as "Express Edit,"106 will enable genome editing to bypass the restrictions imposed by in vitro manipulation of plant tissues. This, in turn, will facilitate the inclusion of genome editing into large-scale breeding programs for crop improvement.

\section{3 | Systems biology-based breeding}

Drought adaptation is a complex trait comprising an intricate regulatory network of phytohormones, transcription factors, and kinases. It is essential to further unfold the direct interactions between these key players and their downstream targets to shortlist most potential candidates for breeding purposes. This demands a systems biology approach to unravel the temporal dynamics and spatial configurations specifying the biological phenomenon of interest.

In plants, cellular processes are typically governed by gene regulatory networks (GRNs) that can influence a trait of agronomic interest. $^{107}$ To design specific crop ideotypes, GRNs can identify the most promising candidate genes, predict the network behavior arising from the altered genes and the resulting phenotypes of the traits modulated by the network. For instance, a limited number of QTLs and candidate genes regulating leaf senescence, an important determinant of drought adaptation, have been identified till date in crops such as wheat. ${ }^{108-111}$ A comprehensive understanding of the network of genes modulating this process may facilitate the development of wheat varieties having a senescence profile tailored to augment nutrient remobilization, while enabling improved yield and adaptation to drought conditions. In a recent study, analyses of gene expression data and GRN modeling led to the identification of key transcriptional regulators (such as NAM-A2) that coordinate flag leaf senescence in wheat. ${ }^{112}$ Such approaches will help to understand network performance and identify breeding targets that are usually not detected by traditional forward- and reversegenetics strategies, and utilize them to manipulate an entire network to build the desired phenotype. Novel insights into the complex associations existing between different adaptive traits and their corresponding genes at the systems level will help to identify preferable haplotypes and to design haplotype-based breeding scheme. In rice, metaexpression analysis together with co-expression network offered insights into the function of multiple genes and their interactions at a systems level, which in turn helped in the selection of desired haplotypes for haplotype-based breeding. ${ }^{12}$ Furthermore, dynamic modeling and virtual mutations have shown promise in determining GRN engineering targets in order to tailor the desired phenotype. ${ }^{113}$ Therefore, upcoming efforts to determine molecular breeding targets should focus on such candidates, and assess the impact of virtual mutations in silico by modifying the network model and capturing transient interactions 
among the GRN. ${ }^{114}$ For drought adaptation in crops, such dynamic models will offer robust support for validating the hypothesis obtained from field experiments and accurately defining technologies for rationalizing breeding strategies.

A systems biology approach will provide hints to detect genetic regulators exercising the largest effect on GRNs, even where gene redundancies, mild-effect genes, or feedback loops hinder traditional gene investigation capabilities. ${ }^{112}$ This approach will be particularly relevant for designing ideotypes for crops with complex genomes and multigenic traits, where systems-scale strategies are predicted to outperform the restrictions of conventional breeding approaches in the context of efficacy and speed.

\subsection{Genomic selection and speed breeding}

Innovations in genomic technologies are of particular relevance for improving future crops. However, it takes multiple years for an improved crop variety to be advanced and released for commercial cultivation due to prolonged breeding cycles, which in turn hampers the gain in productivity. Genomic selection and speed breeding approaches are crucial to address the long breeding cycle issue in crops. Genomic selection, which estimates the genetic merit of breeding lines for complex traits such as drought adaptation and increases the efficiency of selection process, is being successfully deployed in many crop breeding programs (Table 1). A good illustration of its impact came from a recent field evaluation of drought tolerant maize hybrids (called as "AQUAmax" hybrids), which possessed substantially higher yields under both optimal and drought stress conditions. ${ }^{80,115}$ On the other hand, speed breeding by achieving up to six generations per year for wheat, barley, chickpea, and pea using specific and highly controlled environmental conditions such as 22 hour-long photoperiods, has emerged as a popular approach for accelerated crop development. ${ }^{116}$ For custom-designed crops, genomic selection can save time and resources typically for traits that are phenotyped during the final stages of the variety development process and those that are costly to measure, for example, yield. While speed breeding can decrease generation times drastically, the genetic gain associated with this technique can be further improved by applying genomic selection at every generation to choose parents for the next generation (Figure 4). The strategy of combining speed breeding with genomic selection, referred to as "speed GS," holds potential for fastforwarding the rate of genetic gain in crop improvement.

A particular haplotype with the highest genomic estimated breeding value can be determined for each genomic region and demarcated by linkage disequilibrium blocks. Desired haplotypes can then be stacked in a cropping line by using an optimum array of crosses. This approach of combining genomic selection with superior haplotypes, called "haplo-GS," can be integrated with speed breeding to rapidly tailor crop varieties with high performance across multiple adaptive traits. The haplo-GS approach could more precisely illustrate the complex relationships between genotype and phenotype, relative to individual SNPs, ultimately enhancing selection gain per unit of time.

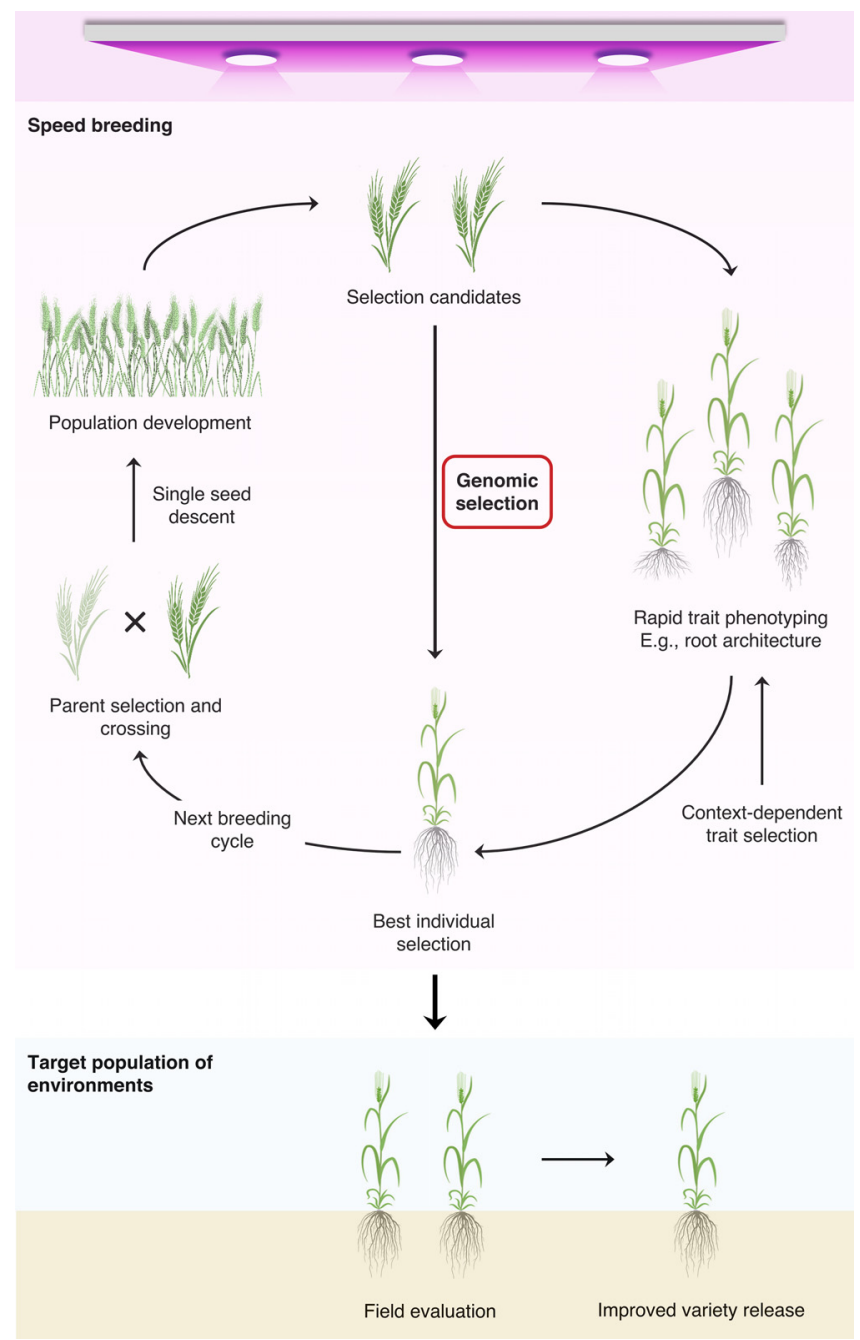

FIG URE 4 Integrating genomic selection and speed breeding to fast-forward genetic gain in crops. The breeding cycle length decreased by genomic selection could be further reduced by performing population development under speed breeding conditions. Selection candidates could be phenotyped for grain yield secondary traits (eg, root architecture) in the glasshouse, and plants that carry the desired trait could be selected. Context-dependent selection of the trait will enable plants to be better adapted to the target environment prior to selecting more complex traits, such as yield. Phenotyping and selecting plants under speed breeding in the glasshouse could further improve selection intensity and the rate of genetic gain

\section{7 | CONCLUSIONS AND PERSPECTIVES}

Future food security will depend on the continuous development of improved crop varieties, which sustain greater yields with minimum agronomic inputs and are better adapted to climate change. Crops can encounter fluctuating drought scenarios, ranging from mild to severe drought episodes at the beginning, mid, or toward the end of the crop cycle. Attributes such as soil depth and constitution, water availability, climate, and management practices also impact crop responses to water deficit. As a result, conceptualizing a drought- 
adaptive ideotype optimized for an array of scenarios may not be possible, but distinct traits related to drought adaptation that are similar across species grown under diverse field conditions could be used as targets for custom-designing crops for specific environments. Developing such designer crops that integrate individually strengthened leaf and root systems, can be simplified by implementing recent technical breakthroughs in crop modeling, second and third-generation sequencing, novel breeding techniques, genome editing, deep learning approaches, and high-throughput phenotyping.

Combining genetic resources and transformative capabilities, ranging from genomic breeding to synthetic biology, will be essential for tailoring crops that improve food security and decrease the impact of agriculture on the environment. Notably, the integration of artificial intelligence (Al) and machine learning algorithms into the processing of hyperspectral images and weather data will enable early-stage prediction of drought scenarios. In turn, the Al system will allow farmers to make more informed decisions at every step of the crop production cycle. Finally, the context-dependent effect of each trait, multiplicity of combined traits, and genotype $\times$ environment interactions for each trait necessitates the use of modeling, to predict the effect of thousands of allele combinations in thousands of fields. This will help to derive a probabilistic approach for identifying the most desirable allelic combinations in a given field/region depending on the scale of the target environment.

A custom-designed crop will be a valuable asset in our attempts to quench agriculture's growing thirst, and maximize productivity while enhancing yield stability in the face of enhancing environmental fluctuations. This ambitious aim needs the collaborative will and efforts of breeders, geneticists, physiologists, systems modelers, and bioinformaticians alike.

\section{ACKNOWLEDGEMENTS}

R.K.V. is grateful to Bill \& Melinda Gates Foundation, USA, and Department of Biotechnology, Ministry of Science \& Technology, and Ministry of Agriculture \& Farmers Welfare of Government of India for supporting research on drought adaptation. Thanks are also due to Science \& Engineering Research Board (SERB) of Department of Science \& Technology (DST), Government of India for providing the J C Bose National Fellowship (SB/S9/Z-13/2019) to R.K.V. for writing this article. R.B. acknowledges the funding support from Council of Scientific and Industrial Research (CSIR), Government of India, for the award of a research fellowship. Y.Q. is supported by NSF grants (IOS1758745 and IOS-2029889) and USDA-NIFA grants (2018-335 22-28789, 2020-33522-32274, and 2020-70029-33161).

\section{CONFLICT OF INTEREST}

The authors declare no competing interests.

\section{AUTHOR CONTRIBUTIONS}

R.K.V. conceived the idea; R.K.V. and R.B. wrote the manuscript. All authors substantially contributed to the discussion of content, and reviewed and/or edited the manuscript before submission.

\section{ORCID}

Rajeev K. Varshney (D) https://orcid.org/0000-0002-4562-9131

Rutwik Barmukh (D) https://orcid.org/0000-0002-2740-8992

Manish Roorkiwal (D) https://orcid.org/0000-0001-6595-281X

\section{REFERENCES}

1. FAO. Proactive approaches to drought preparedness - Where are we now and where do we go from here? (Rome, 2019).

2. FAO. Disasters causing billions in agricultural losses, with drought leading the way. (Rome, 2018). www.fao.org/news/story/en/item/ 1106977/icode/.

3. Trnka M, Feng S, Semenov MA, et al. Mitigation efforts will not fully alleviate the increase in water scarcity occurrence probability in wheat-producing areas. Sci Adv. 2019;5:eaau2406.

4. Kumar A, Dixit S, Ram T, Yadaw RB, Mishra KK, Mandal NP. Breeding high-yielding drought-tolerant rice: genetic variations and conventional and molecular approaches. J Exp Bot. 2014;65:62656278.

5. Baenziger PS, Beecher B, Graybosch RA, et al. Registration of 'NE01643' wheat. J Plant Registration. 2008;2:36-42.

6. Naoman MM, Ahmed IA, El-Sayed AA, et al. Registration of 'Giza 2000' drought-tolerant six-rowed barley for rainfed and new reclaimed areas in Egypt. Crop Sci. 2007;47:440.

7. Tardieu F, Simonneau T, Muller B. The physiological basis of drought tolerance in crop plants: a scenario-dependent probabilistic approach. Annu Rev Plant Biol. 2018;69:733-759.

8. Millet E, Welcker C, Kruijer W, et al. Genome-wide analysis of yield in Europe: allelic effects as functions of drought and heat scenarios. Plant Physiol. 2016;172:749-764.

9. Zhao $\mathrm{Y}$, Thorwarth $\mathrm{P}$, Jiang $\mathrm{Y}$, et al. Unlocking big data doubled the accuracy in predicting the grain yield in hybrid wheat. Sci Adv. 2021; 7:eabf9106.

10. Wang $\mathrm{X}$, Wang $\mathrm{H}$, Liu S, et al. Genetic variation in ZmVPP1 contributes to drought tolerance in maize seedlings. Nat Genet. 2016;48: 1233-1241.

11. Bevan MW, Uauy C, Wulff BBH, Zhou J, Krasileva K, Clark MD. Genomic innovation for crop improvement. Nature. 2017;543: 346-354.

12. Abbai R, Singh VK, Nachimuthu VV, et al. Haplotype analysis of key genes governing grain yield and quality traits across $3 \mathrm{~K}$ RG panel reveals scope for the development of tailor-made rice with enhanced genetic gains. Plant Biotechnol J. 2019;17:1612-1622.

13. Shi J, Gao H, Wang H, et al. ARGOS8 variants generated by CRISPRCas9 improve maize grain yield under field drought stress conditions. Plant Biotechnol J. 2017;15:207-216.

14. Liu L, Zhang J, Xu J, et al. CRISPR/Cas9 targeted mutagenesis of SILBD40, a lateral organ boundaries domain transcription factor, enhances drought tolerance in tomato. Plant Sci. 2020;301:110683.

15. Borrell AK, Mullet JE, George-Jaeggli B, et al. Drought adaptation of stay-green sorghum is associated with canopy development, leaf anatomy, root growth, and water uptake. J Exp Bot. 2014;65:62516263.

16. Caine RS, Yin X, Sloan J, et al. Rice with reduced stomatal density conserves water and has improved drought tolerance under future climatic conditions. New Phytol. 2019;221:371-384.

17. Robbins NE II, Dinneny JR. Growth is required for perception of water availability to pattern root branches in plants. Proc Natl Acad Sci USA. 2018;115:822-831.

18. Uga $Y$, Sugimoto K, Ogawa S, et al. Control of root system architecture by DEEPER ROOTING 1 increases rice yield under drought conditions. Nat Genet. 2013;45:1097-1102.

19. Blum A. Osmotic adjustment is a prime drought stress adaptive engine in support of plant production. Plant Cell Environ. 2017;40: 4-10. 
20. Li Y, Li H, Li Y, Zhang S. Improving water-use efficiency by decreasing stomatal conductance and transpiration rate to maintain higher ear photosynthetic rate in drought-resistant wheat. Crop J. 2017;5: 231-239.

21. Hughes J, Hepworth C, Dutton C, et al. Reducing stomatal density in barley improves drought tolerance without impacting on yield. Plant Physiol. 2017;174:776-787.

22. Jin X, Zarco-Tejada PJ, Schmidhalter U, et al. High-throughput estimation of crop traits: a review of ground and aerial phenotyping platforms. IEEE Trans Geosci Remote Sens. 2020;9:200-231.

23. Liedtke JD, Hunt $\mathrm{CH}$, George-Jaeggli $\mathrm{B}$, et al. High-throughput phenotyping of dynamic canopy traits associated with stay-green in grain sorghum. Plant Phenomics. 2020;2020:4635153.

24. Cuneo IF, Barrios-Masias F, Knipfer T, et al. Differences in grapevine rootstock sensitivity and recovery from drought are linked to fine root cortical lacunae and root tip function. New Phytol. 2021;229: 272-283.

25. Ogura T, Goeschl C, Filiault D, et al. Root system depth in Arabidopsis is shaped by EXOCYST7OA3 via the dynamic modulation of auxin transport. Cell. 2019;178:400-412.

26. Pinto RS, Reynolds MP. Common genetic basis for canopy temperature depression under heat and drought stress associated with optimized root distribution in bread wheat. Theor Appl Genet. 2015;128: 575-585.

27. Orosa-Puente B, Leftley $N$, von Wangenheim $D$, et al. Root branching toward water involves posttranslational modification of transcription factor ARF7. Science. 2018;362:1407-1410.

28. Dietrich D, Pang L, Kobayashi A, et al. Root hydrotropism is controlled via a cortex-specific growth mechanism. Nat Plants. 2017;3: 17057.

29. Liu HS, Li FM. Root respiration, photosynthesis and grain yield of two spring wheat in response to soil drying. Plant Growth Regul. 2005;46:233-240.

30. Bontpart T, Concha C, Giuffrida MV, et al. Affordable and robust phenotyping framework to analyse root system architecture of soilgrown plants. Plant J. 2020;103:2330-2343.

31. Atkinson JA, Pound MP, Bennett MJ, Wells DM. Uncovering the hidden half of plants using new advances in root phenotyping. Curr Opin Biotechnol. 2019;55:1-8.

32. Abid M, Ali S, Qi LK, et al. Physiological and biochemical changes during drought and recovery periods at tillering and jointing stages in wheat (Triticum aestivum L.). Sci Rep. 2018;8:4615.

33. Mahmood T, Abdullah M, Ahmar S, et al. Incredible role of osmotic adjustment in grain yield sustainability under water scarcity conditions in wheat (Triticum aestivum L.). Plants (Basel). 2020;9:1208.

34. Gonzalez A, Martin I, Ayerbe L. Yield and osmotic adjustment capacity of barley under terminal water stress conditions. J Agron Crop Sci. 2008;194:81-91.

35. Moinuddin IP. Evaluation of potassium compared to other osmolytes in relation to osmotic adjustment and drought tolerance of chickpea under water deficit environments. J Plant Nutr. 2007; 30:517-535.

36. Nio SA, Cawthray GR, Wade LJ, Colmer TD. Pattern of solutes accumulated during leaf osmotic adjustment as related to duration of water deficit for wheat at the reproductive stage. Plant Physiol Biochem. 2011;49:1126-1137.

37. Ray DK, Ramankutty N, Mueller ND, West PC, Foley JA. Recent patterns of crop yield growth and stagnation. Nat Commun. 2012;3 1293.

38. Reynolds M, Tuberosa R. Translational research impacting on crop productivity in drought-prone environments. Curr Opin Plant Biol. 2008;11:171-179.

39. Reynolds M, Pask AJD, Hoppitt WJE, et al. Strategic crossing of biomass and harvest index - source and sink - achieves genetic gains in wheat. Euphytica. 2017;213:257.
40. Reynolds M, Langridge P. Physiological breeding. Curr Opin Plant Biol. 2016;31:162-171.

41. Lopes MS, Reynolds MP. Partitioning of assimilates to deeper roots is associated with cooler canopies and increased yield under drought in wheat. Funct Plant Biol. 2010;37:147-156.

42. Blessing $\mathrm{CH}$, Mariette $\mathrm{A}$, Kaloki $\mathrm{P}$, Bramley $\mathrm{H}$. Profligate and conservative: water use strategies in grain legumes. J Exp Bot. 2018;69: 349-369.

43. George-Jaeggli B, Mortlock MY, Borrell AK. Bigger is not always better: reducing leaf area helps stay-green sorghum use soil water more slowly. Environ Exp Bot. 2017;138:119-129.

44. Borrell AK, van Oosterom EJ, Mullett JE, et al. Stay-green alleles individually enhance grain yield in sorghum under drought by modifying canopy development and water uptake patterns. New Phytol. 2014;203:817-830.

45. Parent B, Leclere M, Lacube $S$, et al. Maize yields over Europe may increase in spite of climate change, with an appropriate use of the genetic variability of flowering time. Proc Natl Acad Sci USA. 2018; 115:10642-10647.

46. Kholová J, Murugesan T, Kaliamoorthy S, et al. Modelling the effect of plant water use traits on yield and stay-green expression in sorghum. Funct Plant Biol. 2014;41:1019-1034.

47. Zhao Z, Rebetzke GJ, Zheng B, Chapman SC, Wang E. Modelling impact of early vigour on wheat yield in dryland regions. J Exp Bot. 2019;70:2535-2548.

48. Millet EJ, Kruijer W, Coupel-Ledru A, et al. Genomic prediction of maize yield across European environmental conditions. Nat Genet. 2019;51:952-956.

49. Medina V, Gilbert ME. Physiological trade-offs of stomatal closure under high evaporative gradients in field grown soybean. Funct Plant Biol. 2015;43:40-51.

50. Nuccio ML, Wu J, Mowers R, et al. Expression of trehalose6-phosphate phosphatase in maize ears improves yield in wellwatered and drought conditions. Nat Biotechnol. 2015;33:862-869.

51. Siddique MN, Léon J, Naz AA, Ballvora A. Genetics and genomics of root system variation in adaptation to drought stress in cereal crops. J Exp Bot. 2021;72:1007-1019.

52. Balanos J, Edmeades GO, Martinez L. Eight cycles of selection for drought tolerance in lowland tropical maize. III. Responses in drought-adaptive physiological and morphological traits. Field Crop Res. 1993;31:269-286.

53. Campos H, Cooper A, Habben JE, Edmeades GO, Schussler JR. Improving drought tolerance in maize: a view from industry. Field Crop Res. 2004;90:19-34.

54. Purushothaman R, Krishnamurthy L, Upadhyaya HD, Vadez V, Varshney RK. Genotypic variation in soil water use and root distribution and their implications for drought tolerance in chickpea. Funct Plant Biol. 2017;44:235-252.

55. Kong $X$, Zhang $M$, De Smet I, Ding Z. Designer crops: optimal root system architecture for nutrient acquisition. Trends Biotechnol. 2014; 32:597-598.

56. Álvaro F, Isidro J, Villegas D, García del Moral LF, Royo C. Breeding effects on grain filling, biomass partitioning, and remobilization in Mediterranean durum wheat. Agron J. 2008;100:361-370.

57. Perry MW, D'Antuono MF. Yield improvement and associated characteristics of some Australian spring wheat cultivars introduced between 1860 and 1982. Aust J Agric Res. 1989;40:457-472.

58. Cooper M, Tang T, Gho C, Hart T, Hammer G, Messina C. Integrating genetic gain and gap analysis to predict improvements in crop productivity. Crop Sci. 2020;60:582-604.

59. von Wettberg EJB, Chang PL, Basdemir F, et al. Ecology and genomics of an important crop wild relative as a prelude to agricultural innovation. Nat Commun. 2018;9:649.

60. Varshney RK, Thudi M, Roorkiwal $M$, et al. Resequencing of 429 chickpea accessions from 45 countries provides insights into 
genome diversity, domestication and agronomic traits. Nat Genet. 2019;51:857-864.

61. Khazaei H, Street K, Bari A, Mackay M, Stoddard FL. The FIGS (focused identification of germplasm strategy) approach identifies traits related to drought adaptation in Vicia faba genetic resources. PLoS One. 2013;8:e63107.

62. Reynolds $M$, Tattaris $M$, Cossani CM, Ellis M, YamaguchiShinozaki K, Pierre CS. Advances in Wheat Genetics: From Genome to Field. Tokyo, Japan: Springer; 2015.

63. Rasheed A, Hao Y, Xia X, et al. Crop breeding chips and genotyping platforms: progress, challenges, and perspectives. Mol Plant. 2017; 10:1047-1064.

64. Placido DF, Campbell MT, Folsom JJ, et al. Introgression of novel traits from a wild wheat relative improves drought adaptation in wheat. Plant Physiol. 2013;161:1806-1819.

65. Wang W, Mauleon M, Hu Z, et al. Genomic variation in 3,010 diverse accessions of Asian cultivated rice. Nature. 2018;557:43-49.

66. Varshney RK, Roorkiwal M, Sun S, et al. A global reference for chickpea genetic variation based on the sequencing of 3,366 genomes. Nature. 2021;526(7571):68-74.

67. Ramu P, Esuma W, Kawuki R, et al. Cassava haplotype map highlights fixation of deleterious mutations during clonal propagation. Nat Genet. 2017;49:959-963.

68. Johnsson M, Gaynor RC, Jenko J, Gorjanc G, de Koning DJ, Hickey JM. Removal of alleles by genome editing (RAGE) against deleterious load. Genet Sel Evol. 2019;51:14.

69. Varshney RK, Bohra A, Yu J, Graner A, Zhang Q, Sorrells ME. Designing future crops: genomics-assisted breeding comes of the age. Trends Plant Sci. 2021;26:631-649.

70. Gautam T, Amardeep, Saripalli G, et al. Introgression of a drought insensitive grain yield QTL for improvement of four Indian bread wheat cultivars using marker assisted breeding without background selection. J Plant Biochem Biotechnol. 2021;30:172-183.

71. Kholová J, Hash CT, Kumar PL, Yadav RS, Kočová M, Vadez V. Terminal drought-tolerant pearl millet [Pennisetum glaucum (L.) R. Br.] have high leaf $A B A$ and limit transpiration at high vapour pressure deficit. J Exp Bot. 2010;61:1431-1440.

72. Kholová J, Hash CT, Kakkera A, Kočová M, Vadez V. Constitutive water conserving mechanisms are correlated with the terminal drought tolerance of pearl millet [Pennisetum glaucum (L.) R. Br.]. J Exp Bot. 2010;61:369-377.

73. Varshney RK, Gaur PM, Chamarthi SK, et al. Fast-track introgression of "QTL-hotspot" for root traits and other drought tolerance traits in JG 11, an elite and leading variety of chickpea. Plant Genome. 2013;6:1-9.

74. Bharadwaj C, Tripathi S, Soren KR, et al. Introgression of "QTLhotspot" region enhances drought tolerance and grain yield in three elite chickpea cultivars. Plant Genome. 2020;14:e20076.

75. Dixit S, Singh A, Sandhu N, Bhandari A, Vikram P, Kumar A. Combining drought and submergence tolerance in rice: marker-assisted breeding and QTL combination effects. Mol Breed. 2017;37:143.

76. Shamsudin NAA, Swamy BPM, Ratnam W, et al. Pyramiding of drought yield QTLs into a high quality Malaysian rice cultivar MRQ74 improves yield under reproductive stage drought. Rice (N Y). 2016;9:21.

77. Bankole F, Menkir A, Olaoye G, et al. Genetic gains in yield and yield related traits under drought stress and favorable environments in a maize population improved using marker assisted recurrent selection. Front Plant Sci. 2017;8:1-11.

78. Beyene $\mathrm{Y}$, Semagn $\mathrm{K}$, Crossa J, et al. Improving maize grain yield under drought stress and non-stress environments in sub-Saharan Africa using marker-assisted recurrent selection. Crop Sci. 2016;56: 344-353.

79. Vivek BS, Krishna GK, Vengadessan V, et al. Use of genomic estimated breeding values results in rapid genetic gains for drought tolerance in maize. Plant Genome. 2017;10:1-8.
80. Gaffney J, Schussler J, Loffler C, et al. Industry-scale evaluation of maize hybrids selected for increased yield in drought-stress conditions of the US Corn Belt. Crop Sci. 2015;55:1608-1618.

81. Beyene $\mathrm{Y}$, Semagn K, Mugo S, et al. Genetic gains in grain yield through genomic selection in eight bi-parental maize populations under drought stress. Crop Sci. 2015;55:154-163.

82. Kumar VVS, Verma RK, Yadav SK, et al. CRISPR-Cas9 mediated genome editing of drought and salt tolerance (OsDST) gene in Indica mega rice cultivar MTU1010. Physiol Mol Biol Plants. 2020;26:10991110.

83. Curtin SJ, Xiong Y, Michno J-M, et al. CRISPR/Cas9 and TALENs generate heritable mutations for genes involved in small RNA processing of Glycine max and Medicago truncatula. Plant Biotechnol J. 2018;16:1125-1137.

84. United Nations Convention to Combat Desertification (UNCCD). Desertification: The Invisible Frontline. 2014. www.unccd.int/ publications/desertification-invisible-frontline-second-edition. Accessed August 3, 2021.

85. Peleman JD, Van der Voort JR. Breeding by design. Trends Plant Sci. 2003;8:330-334.

86. Guo D, Jiang H, Yan W, et al. Resequencing 200 flax cultivated accessions identifies candidate genes related to seed size and weight and reveals signatures of artificial selection. Front Plant Sci. 2020;10:1682.

87. Chin C-S, Peluso P, Sedlazeck FJ, et al. Phased diploid genome assembly with single molecule real-time sequencing. Nat Methods. 2016;13:1050.

88. Sinha P, Singh VK, Saxena RK, et al. Superior haplotypes for haplotype-based breeding for drought tolerance in pigeonpea (Cajanus cajan L.). Plant Biotechnol J. 2020;18:2482-2490.

89. Scheben A, Edwards D. Towards a more predictable plant breeding pipeline with CRISPR/Cas-induced allelic series to optimize quantitative and qualitative traits. Curr Opin Plant Biol. 2018;45:218-225.

90. Abdallah NA, Prakash CS, McHughen AG. Genome editing for crop improvement: challenges and opportunities. GM Crops Food. 2015;6: 183-205.

91. Zhu H, Li C, Gao C. Applications of CRISPR-Cas in agriculture and plant biotechnology. Nat Rev Mol Cell Biol. 2020;21:661-677.

92. Gaudelli NM, Komor AC, Rees HA, et al. Programmable base editing of $A \bullet T$ to $G \bullet C$ in genomic DNA without DNA cleavage. Nature. 2017;551:464-471.

93. Komor AC, Kim YB, Packer MS, Zuris JA, Liu DR. Programmable editing of a target base in genomic DNA without double-stranded DNA cleavage. Nature. 2016;533:420-424.

94. Ren Q, Sretenovic S, Liu S, et al. PAM-less plant genome editing using a CRISPR-SpRY toolbox. Nat Plants. 2021;7:25-33.

95. Jupe F, Rivkin AC, Michael TP, et al. The complex architecture and epigenomic impact of plant T-DNA insertions. PLoS Genet. 2019;15: e1007819.

96. Woo JW, Kim J, Kwon SI, et al. DNA-free genome editing in plants with preassembled CRISPR-Cas9 ribonucleoproteins. Nat Biotechnol. 2015;33:1162-1164.

97. Malnoy $M$, Viola $\mathrm{R}$, Jung $\mathrm{M}-\mathrm{H}$, et al. DNA-free genetically edited grapevine and apple protoplast using CRISPR/Cas9 ribonucleoproteins. Front Plant Sci. 2016;7:1904.

98. Liang Z, Chen K, Li T, et al. Efficient DNA-free genome editing of bread wheat using CRISPR/Cas9 ribonucleoprotein complexes. Nat Commun. 2017;8:14261.

99. Ma X, Zhang X, Liu H, Li Z. Highly efficient DNA-free plant genome editing using virally delivered CRISPR-Cas9. Nat Plants. 2020;6: 773-779.

100. Kim H, Kim ST, Ryu J, Kang BC, Kim JS, Kim SG. CRISPR/Cpf1-mediated DNA-free plant genome editing. Nat Commun. 2017;8:14406.

101. Ming M, Ren Q, Pan C, et al. CRISPR-Cas12b enables efficient plant genome engineering. Nat Plants. 2020;6:202-208. 
102. McCarty NS, Graham AE, Studená L, Ledesma-Amaro R. Multiplexed CRISPR technologies for gene editing and transcriptional regulation. Nat Commun. 2020;11:1281.

103. Rodríguez-Leal D, Lemmon ZH, Man J, Bartlett ME, Lippman ZB. Engineering quantitative trait variation for crop improvement by genome editing. Cell. 2017;171:470-480.

104. Li T, Yang X, Yu Y, et al. Domestication of wild tomato is accelerated by genome editing. Nat Biotechnol. 2018;36:1160-1163.

105. Pan C, Sretenovic S, Qi Y. CRISPR/dCas-mediated transcriptional and epigenetic regulation in plants. Curr Opin Plant Biol. 2021;60: 101980.

106. Hickey LT, Hafeez AN, Robinson H, et al. Breeding crops to feed 10 billion. Nat Biotechnol. 2019;37:744-754.

107. Walley JW, Sartor RC, Shen Z, et al. Integration of omic networks in a developmental atlas of maize. Science. 2016;353:814-818.

108. Verma V, Foulkes MJ, Worland AJ, Sylvester-Bradley R, Caligari PDS, Snape JW. Mapping quantitative trait loci for flag leaf senescence as a yield determinant in winter wheat under optimal and drought-stressed environments. Euphytica. 2004;135:255-263.

109. Wang S, Liang Z, Sun D, et al. Quantitative trait loci mapping for traits related to the progression of wheat flag leaf senescence. J Agric Sci. 2015;153:1234-1245.

110. Uauy C, Distelfeld A, Fahima T, Blechl A, Dubcovsky J. A NAC gene regulating senescence improves grain protein, zinc, and iron content in wheat. Science. 2006;314:1298-1301.

111. Zhao D, Derkx AP, Liu D-C, Buchner P, Hawkesford MJ. Overexpression of a NAC transcription factor delays leaf senescence and increases grain nitrogen concentration in wheat. Plant Biol. 2015;17: 904-913.

112. Borrill P, Harrington SA, Simmonds J, Uauy C. Identification of transcription factors regulating senescence in wheat through gene regulatory network modeling. Plant Physiol. 2019;180:1740-1755.

113. Scardoni G, Montresor A, Tosadori G, Laudanna C. Node interference and robustness: performing virtual knock-out experiments on biological networks: the case of leukocyte integrin activation network. PLoS One. 2014;9:e88938.

114. Alvarez JM, Schinke A-L, Brooks MD, et al. Transient genome-wide interactions of the master transcription factor NLP7 initiate a rapid nitrogen-response cascade. Nat Commun. 2020;11:1157.

115. Cooper M, Messina CD, Podlich D, et al. Predicting the future of plant breeding: complementing empirical evaluation with genetic prediction. Crop Pasture Sci. 2014;65:311-336.

116. Watson A, Ghosh S, Williams MJ, et al. Speed breeding is a powerful tool to accelerate crop research and breeding. Nat Plants. 2018;4: 23-29.

How to cite this article: Varshney RK, Barmukh R,

Roorkiwal $\mathrm{M}$, et al. Breeding custom-designed crops for improved drought adaptation. Advanced Genetics. 2021;2(3): e202100017. doi:10.1002/ggn2.202100017 